\title{
Stanford argues over costs
}

\section{Boston}

WITH the highest research overhead costs in the United States, Stanford University and its outspoken president, Donald Kennedy, have long been at the centre of the tortuous debate over the standards by which Stanford and other universities calculate overhead charges to the government when they receive federal research grants. Last week, in a new twist to the story, the university revealed that three separate investigations into the university's practices for recovering overhead costs associated with federally-sponsored research are now under way. In addition to Stanford's own "internal audit", branches of Congress and the Defense Department will review the school's practices, with millions of dollars of research funds potentially at stake.

The most explosive investigation is being led by the Office of Naval Research (ONR), the branch of the Defense Department responsible for negotiating the overhead cost rates with Stanford on behalf of all federal agencies. An internal memorandum from a field representative of the ONR that came to light last week accuses Stanford officials of possible "abuse" and "distortion" in their calculation of overhead costs. The letter concludes that "Stanford engaged in fraudulent acts, and, at a minimum, false statements and false claims". Curiously, senior officials at ONR say that they never received the memorandum, which is dated 6 March 1990. Both Stanford and ONR officials claim to have learned of the accusations only recently whien the memorandum surfaced as part of a request under the Freerlom of Information Act from a local California newspaper. Because of the seriousness of the accusations, ONR has launched a full-scale investigation.

The issue is complex and divisive well beyond the specific confines of the ONR investigation, however. Congressman John Dingell, whose congressional subcommittee has also now begun to investigate the overhead issue, informed Kennedy last month that "escalating overhead rates" at Stanford and other universities have prompted his committee's investigation, which will begin with Stanford but will ultimately review practices at other US universities.

Congressional staff members say that the investigation seeks to determine "exactly what the government is paying for" when it allots hundreds of millions of dollars in overhead charges. Stanford alone, for instance, received some \$91 million in overhead costs last year.

Not surprisingly, university administrators, facing rising energy and operating costs, are conscious that the fate of their institutions is bound up in the overhead issue. As for specific charges against Stanford, Kennedy stated last week that university staff responsible for indirect cost matters "enjoy excellent reputations in their professions" and will "cooperate fully with all investigations". But he said that university officials will not comment on the allegations until the investigations are complete.

Stanford faculty members protested strongly last spring that Stanford's rising overhead cost rates - now 78 per cent - were affecting their ability to attract federal grants. Competing researchers, they maintained, were "underselling" them because competitors could conduct the same research at other institutions for less total cost to the government.

Under the current system, universities are allowed to recover overhead, or indirect costs, associated with their researchers' grant proposals through a complex set of guidelines. These indirect costs are computed as a percentage of a modified version of the total direct costs associated with a research project; they can include charges for the university's costs of utilities, building maintenance, the depreciation of new facilities, library use and other administrative costs. Thus, if a Stanford researcher's federal grant has a "modified total direct cost" (for researchers' salaries and the like) of $\$ 100,000$, the federal agency dispensing the grant will be asked to pay $\$ 178,000$ to cover Stanford's share of indirect costs. By comparison, indirect cost rates at MIT, Yale and Columbia are 62 per cent, 68 per cent, and 74 per cent respectively.

As high as those indirect cost rates sound, Larry Horton, Stanford's associate vice president and director of government relations, emphasizes that the percentages themselves are misleading. The rates, he points out, are applied only to a certain portion of a given federal research grant. Thus, Horton maintains that, of total federal funds allotted to Stanford for research, the government actually paid some 43 per cent in overhead charges. However, many researchers still believe that the indirect cost rates are out of control, and government officials complain that many private foundations, such as the American Cancer Society, refuse to pay overhead costs, leaving federal funders to shoulder a disproportionate share.

The controversy surrounding the issue of indirect costs is a longstanding one. Nonetheless, all involved in the current controversy at Stanford predict that the newest round of investigations will once again bring the issue prominently before the public and could provoke new limitations on the indirect costs deemed admissible from universities to the federal government.
GE sees patent storm rising

\section{Washington}

Who first thought that isotopically pure diamonds might be the best room-temperature heat-conductors ever created, with a host of possible applications in the electronics industry? General Electric (GE) took credit for the manufacture of the first such pure diamonds at a press conference earlier this year. But Russell Seitz, a Cambridge (Massachusetts) materials scientist, claims that he predicted the high room-temperature thermal conductivity of isotope-enhanced ciiamonds in a 1975 patent, and told GE researchers about it in 1986.

Most scientists might turn to their lawyer when they suspect someone has borrowed their ideas, but Seitz has instead enlisted the aid of bestselling techno-thriller author Tom Clancy, who used Seitz's predictions about diamonds in The Cardinal of the Kremlin, and a host of famous scientists to persuade the GE board of directors to give him some credit for the work.

In a letter to be sent to GE this week (with a covering letter from Clancy), physicists Philip Morrison and Richard Wilson from Massachusetts Institute of Technology and Harvard respectively, join such notable researchers as artificial intelligence pioneer Marvin Minsky and former presidential science adviser George Keyworth in arguing Seitz's case. "In denying Seitz's seminal role in the development of mono-isotopic diamond ..., GE has not only failed to live up to its own reputation as an ethical firm, but has transgressed the norms of professional scientific conduct", the letter charges.

GE board members have not yet seen the letter but others at GE reject Seitz's claim. Walter Robb, senior vice president for corporate research and development, says that Seitz is one among many who speculated on the effect. "I suppose in the press release and technical article we could have listed all 10 or 20 authors that commented on this effect . . . if we had mentioned a number of them he (Seitz) probably would not have been in the list".

Seitz says that he described the effect discovered by GE at a 1987 talk attended by GE scientists. But GE scientist William Banholzer says that "If he did make such a prediction, it was nothing more than speculation ... He's had three years to publish it in a refereed journal. Where is it?"

Seitz and GE researchers will have a chance to reconcile their differences next week at a Washington, DC, scientific meeting at which both will present papers. Clancy will be giving an after-dinner speech and Seitz hopes it will be one "congratulating GE" on giving recognition to his contribution.

Christopher Anderson \&Alun Anderson 